\title{
Epidemiology and visual outcome of severe eye injuries in a tertiary center of Gandaki Province of Nepal
}

\author{
Kripa Joshi* (iD, Khem Raj Kaini², Kirti Nath Jha ${ }^{3}$, \\ Niraj Man Shrestha ${ }^{4}$, Srijana Thapa Godar ${ }^{5}$ \\ 'Tilganga Institute of Ophthalmology, Kathmandu, Nepal, ${ }^{2}$ Department of Ophthalmology, Manipal college \\ of Medical Sciences, Pokhara, Nepal, ${ }^{3}$ Department of Ophthalmology, Mahatma Gandhi Medical College \\ and Research Institute, Puducherry, India, ${ }^{4}$ Department of Orthopaedics, Manmohan memorial Hospital, \\ Kathmandu, Nepal, ${ }^{5}$ Department of Ophthalmology, Manipal college of Medical Sciences, Pokhara, Nepal \\ Manipal College of Medical Sciences and Teaching Hospital, Pokhara, Nepal.
}

\begin{abstract}
Introduction: Ocular trauma is an important worldwide preventable public health problem which may lead to permanent visual impairment. This study aims to determine the demographics, clinical profile and visual outcome of severe eye injuries. Methods: This study was conducted at a tertiary centre from January 2013 to August 2014. Cases of severe eye injuries hospitalized at or presenting to emergency/OPD were included in the study. All cases underwent detailed examination and necessary intervention. Cases were followed upto 3 months and final visual outcome was evaluated. Results: The study comprised of 60 individuals ( 65 eyes); $76.7 \%$ males and $23.3 \%$ females. Out of 60 cases, the age group 1-9 years had the highest occurrence with $23.33 \%$ followed by $20-29$ years with $20 \%$ and majority were students $45 \%$. Impact with stone was the commonest cause of injury reported on $21.7 \%$ followed by road traffic accident (RTA) 20\%. Closed-globe injuries accounted for 36.6\% and open-globe injuries for 33.3\%. At the time of presentation, visual acuity of less than $6 / 18$ was seen in $71.6 \%$ and at follow up was seen in $45 \%$. Among total cases, $63.3 \%$ eyes were managed conservatively, $30 \%$ eyes underwent surgery and $6.7 \%$ were referred to higher centre for vitreoretinal surgeries. Conclusions: Severe eye injuries were seen in $0.13 \%$ of total eye injuries. Paediatric and young adult males formed the majority of victims. Stone and road traffic accidents were the common causes. One fourth of the eyes were blind. Primary prevention and management of the affected cases is the clear need.
\end{abstract}

Keywords: visual outcome, epidemiology, severe ocular trauma

\section{*Correspondence:}

Dr. Kripa Joshi, MBBS, MS

Tilganga Institute of Ophthalmology,

Kathmandu, Nepal

Email: krips joshi@hotmail.com

Submitted: February 22, 2021

Accepted: June 14, 2021

To cite: Joshi K, Kaini KR, Jha KN, Shrestha N, Godar ST. Epidemiology and visual outcome of severe eye injuries in a tertiary center of Gandaki Province of Nepal. JGMC Nepal. 2021;14(1):63-7.

DOI: $10.3126 /$ jgmcn.v14i1.30936

\section{INTRODUCTION}

Ocular injury is one of the major causes of preventable monocular blindness and visual impairment in the world and in developing countries..$^{1-4}$ The impact of ocular trauma in community is potentially enormous and is associated with direct and indirect costs because of cost of treatment and lost days of work as the majority of ocular injuries are sustained by active and productive individuals. ${ }^{5,6}$

The survey results published by the US National Society to Prevent Blindness states that eye injuries can be considered second only to cataracts as the most common cause of visual impairment. ${ }^{4}$ The Nepal Eye Study based on 1981 Nepal Blindness survey estimated trauma as the second leading cause of unilateral blindness, accounting for $13.6 \%$. An estimated survey showed $7.9 \%$ of all blindness in Nepal is caused by ocular trauma. ${ }^{8}$

The epidemiology of ocular trauma vulnerable age group, place 
and source of injury provide valuable measures in ocular injuries prevention. Data on severe eye injuries are scarce. This study aims to fill this information gap so critical for planning interventions to prevent blindness and visual impairment.

\section{METHODS}

We conducted a hospital based cross sectional study at a tertiary health care centre in hilly region of Nepal from January 2013 to August 2014. The ethical clearance was obtained from the institutionl review committee of Manipal College of Medical Sciences. Cases of severe eye injuries hospitalised at or presenting to emergency/OPD of tertiary care hospital during the study period and who gave informed consent were included in the study. A severe eye injury is defined as one which resulted in permanent and significant (measurable and observable on routine eye examination) structural and/or functional changes to the eye. $^{7}$

Informed consent was obtained from patients and from parents or guardians in case of children, and confidentiality was maintained. The detailed history, about time, place of injury, mode of injury was collected. Examination included Snellen's visual acuity test, examination of extraocular motility, slit lamp examination. Posterior segment examination was done wherever possible either by 90D lens, direct ophthalmoscope or indirect ophthalmoscope. Mechanical injuries were classified according to Birmingham eye trauma terminology (BETT) system proposed by Kuhn and co workers. Relevant investigations like X ray, CT scan, B scan, MRI were done as per need. Patients were treated and referred as per need.

Eye examination (anterior and posterior segment) including visual acuity was done on follow-up at 3 weeks, 6 weeks \& 3 months. The sample size calculations was based on a standard formula Henderson and Sundareson $\mathrm{N}=\mathrm{z}^{2} \mathrm{pq} / \mathrm{d}^{2}$. Descriptive statistics, frequencies, percentages, mean, standard deviation were determined. Data of each case was entered in a specially designed proforma and the whole data was analyzed using a Statistical package for social science (SPSS) program version 20. We included 60 cases (65 eyes) of severe eye injuries.

\section{RESULTS}

Cases included 65 eyes of 60 individuals with severe eye injuries. Figure 1 gives the age distribution of the patients. The youngest age group 1-9 years had the highest occurrence with $23.33 \%$ followed by $20-29$ years with $20 \%$ (figure1). Mean age of subjects was 26.50土 18.88 (range 1-94yrs). There were 46 (76.6\%) males and 14 (23.3\%) females with male: female ratio 3.3:1. The right eye was injured more frequently 34 eyes $(56.7 \%)$ than the left eye. Students and farmers more often suffered severe eye injuries with $45 \%$ and $21.7 \%$ respectively. The commonest place of occurrence was seen in field 35\%; followed by road $31.7 \%$. Table 1 details the gender distribution, laterality, occupation and place of occurrence.

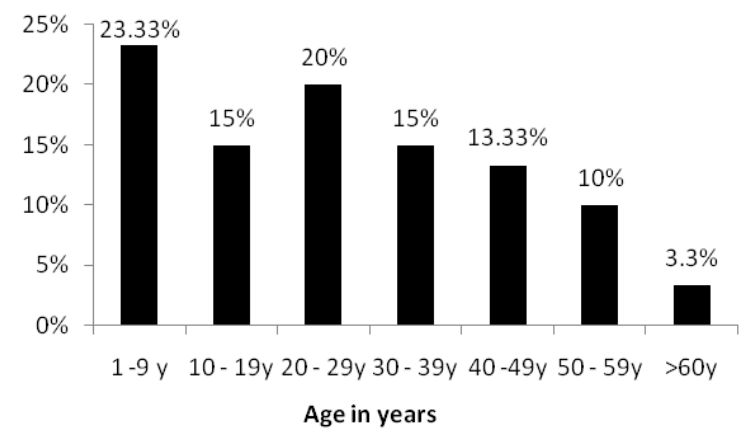

Fig 1. Age distribution of patients with severe ocular trauma

Table 1: Demographic characteristics and settings of severe eye injuries $(n=60)$

\begin{tabular}{llcc}
\hline \multirow{4}{*}{ Gender } & \multicolumn{1}{c}{ Variables } & Frequency & Percent \\
& Male & 46 & 76.67 \\
& Female & 14 & 23.33 \\
Eye involvement & Bilateral & 5 & 8.3 \\
& Unilateral (Right eye) & 34 & 56.7 \\
& Unilateral (Left eye) & 21 & 35 \\
& Student & 27 & 45 \\
Occupation & Farmer & 13 & 21.7 \\
& Business (shopkeeper/vendor) & 8 & 13.3 \\
& Private service (salaried/factory) & 6 & 10.0 \\
& Day/unskilled labour & 3 & 5 \\
& Baby & 3 & 5 \\
& Field & 21 & 35 \\
& Road & 19 & 31.67 \\
& Home & 14 & 23.33 \\
& School/hospital premises & 6 & 10 \\
\hline
\end{tabular}

Regarding mode of injury, play/sports and accidental trauma at work each accounted $33.3 \%$ of injuries, road traffic accidents accounted 20\%of cases. Ten percent of injuries were results of assault. Impact with stone was the commonest $(21.7 \%)$ source of injury. Vehicular accident and wooden stick accounted for $20 \%$ and $15 \%$ each, sharp objects $8.3 \%$, fall from height and chemical injury each $6.7 \%$. Nearly half of the cases $(51.7 \%)$ presented within twenty-four hours of the injury and $28.3 \%$ within 3 days, $15 \%$ within 3 days to 7 days and $5 \%$ after 7 days.

Table 2 shows visual acuity at presentation. Among bilateral involvement, 2 cases presented with VA of $3 / 60$ to $1 / 60,1$ 
case presented with $1 / 60$ to perception of light, 1 with VA of $6 / 60$ to $3 / 60$ and 1 case with VA of $6 / 6$ to $6 / 18$.

Table 2: VA at time of presentation

\begin{tabular}{lcc}
\hline \multicolumn{1}{c}{ Visual Acuity } & $\begin{array}{c}\text { At presentation (number of bilateral eye) } \\
\mathbf{n = 6 0}\end{array}$ & Frequency(\%) \\
6/6-6/18 & $13+1^{*}$ & 23.33 \\
$6 / 18-6 / 60$ & 12 & 20 \\
$6 / 60-3 / 60$ & $1+1^{*}$ & 3.33 \\
$3 / 60-1 / 60$ & $6+2^{*}$ & 13.33 \\
$1 / 60-P L$ & $16+1^{*}$ & 28.33 \\
NPL & 4 & 6.66 \\
could not be elicited & 3 & 5 \\
\hline
\end{tabular}

* denotes number of bilateral eye involved

Closed globe injury was seen in $36.66 \%(n=22)$ cases; zone I in $16.66 \%(n=10)$ zone II in $5 \%(n=3)$ and zone III in $15 \%(n=9)$. Open globe injury was seen in $33.33 \%(n=20)$ cases; zone I in $18.33 \%(n=11)$ zone II in $11.66 \%(n=7)$ and zone III in $3.33 \%(n=2)$. Among open globe injuries, 8 cases had uvea prolapsed.

Burn injury was seen in 6 cases, chemical injury in 4 and thermal injury in 2 cases. Orbital wall fracture was seen in 17 cases. Among them 7 cases had orbital floor fracture, 3 had orbital roof fracture, 1 had medial wall fracture, 4 had floor and medial wall fracture and 2 had roof and medial wall fracture. Other findings is shown in table 3.

Table 3: Nature of injuries

\begin{tabular}{lc}
\hline \multicolumn{1}{c}{ Nature of injuries } & Number of eyes (\%) \\
eyelid laceration without canaliculi obstruction & $6(10)$ \\
eyelid laceration with canaliculi obstruction & $1(1.66)$ \\
corneal laceration & $23(38)$ \\
corneal ulcer & $5(8.3)$ \\
hyphema & $5(8.3)$ \\
Traumatic iridocyclitis & $2(3.3)$ \\
traumatic cataract & $12(20)$ \\
vitreous haemorrhage & $4(6.6)$ \\
retinal tear with retinal detachment & $5(8.3)$ \\
berlin's edema & $1(1.66)$ \\
traumatic optic neuropathy & $7(11.6)$ \\
enophthalmos & $3(5)$ \\
extraocular muscle palsy & $2(3.3)$ \\
\hline
\end{tabular}

Among them bilateral vitreous haemorrhage was seen in 1 case. Out of total, $63.3 \%$ of cases were managed conservatively, 30\% were managed by surgery. Four cases $(6.7 \%)$ needed referral to higher centre for vitreoretinal surgeries.

Corneoscleral repair was done for $n=5$ (8.3\%) cases, eyewall repair with anterior chamber wash was done for $\mathrm{n}=7(11.7 \%)$ cases, eyewall repair with iris reposition for $n=3(5 \%)$ and abscission was done for $n=2(3.3 \%)$, ocular adnexa repair for $n=3(5 \%)$ and evisceration was required in $2(3.3 \%)$ cases.

Visual acuity at follow up is shown in table no.4. Among bilateral involvement, 4 cases had BCVA of $6 / 6$ to $6 / 18$ in each eye and 1 case had BCVA of $6 / 60$ to $3 / 60$ in one eye and $3 / 60$ to $1 / 60$ in the other eye (table 5). During the follow up period, endophthalmitis was seen in 1 case and angle closure glaucoma with retinal detachment in 1 case.

Table 4: Visual acuity at follow up

\begin{tabular}{lcc}
\hline \multicolumn{1}{c}{ Visual Acuity } & $\begin{array}{c}\text { At follow up } \\
\text { (number of bilateral eye) } \mathbf{n = 6 0}\end{array}$ & Frequency(\%) \\
$6 / 6-6 / 18$ & $26+4^{*}$ & 50 \\
$6 / 18-6 / 60$ & 7 & 11.66 \\
$6 / 60-3 / 60$ & $4+1^{* *}$ & 7.5 \\
$3 / 60-1 / 60$ & $3+1^{* *}$ & 5.8 \\
1/60-PL & 8 & 13.3 \\
NPL & 4 & 6.66 \\
could not be elicited & 3 & 5 \\
\hline
\end{tabular}

* number of bilateral eye involved, ${ }^{* *}$ single eye Visual acuity (VA) of bliateral involved eye

\section{DISCUSSION}

Ocular trauma is a major cause of worldwide visual impairment and morbidity. ${ }^{4}$ This study is helpful in defining the frequency, distribution, causes and other underlying factors related to traumatic injuries. Our study showed number of severe ocular trauma cases to be 60 out of 45,891 cases listed during this period that accounts $0.13 \%$ in total ocular trauma cases and majority of them was seen among age group 1-9 years(23.3\%) followed by 20-29 years (20\%). Children and economically earning groups are more victimised similar to the study conducted by Ilsar et al. ${ }^{9}$ which concluded peak incidence of ocular injuries among 21-30 (21\%) age and 0-10 (18.5\%) age. Similarly May et al. ${ }^{7}$ study suggested less than 30 years are frequently involved in study of serious eye injuries in US injury registry. Godar et al. ${ }^{20}$ and Sthapit et al. ${ }^{21}$ study showed average age group was $28.89 \pm 19.06$ years and $28.43 \pm 16.36$ years respectively. These groups are outgoing groups, they have high physical activitiy, thus more exposed to varying surroundings and vulnerable to injuries. Children are more susceptible due to their immature motor skills and reduced ability to avoid or detect dangers. ${ }^{11}$ The study showed male: female ratio of 3.3:1 could be explained to the adventurous nature of boys and engagement in outdoor activities where trauma will be highly encountered. To some extent, it may be due to higher reporting of injuries occurring in male to hospital than females as we have male preferential society.

Students and farmers were seen as more prone to severe 
ocular injuries similar to studies done by Malla ${ }^{22}$ and Khatry et al. ${ }^{12}$ Our study showed severe eye injuries were related to sports $33.3 \%(\mathrm{n}=20)$, injuries related to work $33.33 \%(n=20)$ followed by road traffic accidents $20 \%$ $(n=12)$. Similar findings were found in other studies. ${ }^{10,13}$ In our study, the commonest source of injury was blunt trauma by stone $22 \%$ followed by vehicular accidents $20 \%$ similar to other studies. ${ }^{14-16,20,22}$ The reason may be because this study is done in mountainous part of country covered with stones.

In this study, the time period between trauma and presentation to hospital was within 24 hours in $51.7 \%$ cases, similar to study by Voon et al. ${ }^{10}$ that concluded $55.5 \%$ presented within 24 hours and Sthapit et al. ${ }^{21}$ which concluded $54.5 \%$ presented within 24 hours, however, $43.3 \%$ cases presented within 1-7 days in our studymay be explained due to decreased public awareness, health education and transportation facility. Closed globe injuries were seen more frequently to occur than open globe injuries. This is consistent with studies done by Kinderan et al. ${ }^{17}$ which concluded closed globe injuries to be $73.3 \%$ and $68.33 \%$ by Misra et al. ${ }^{18}$

At the time of presentation $23.3 \%$ cases presented with VA of $6 / 6$ to $6 / 18$ increased to $50 \%$ in follow up after treatment. VA of $6 / 18$ to $6 / 60$ was seen in $n=12(20 \%)$ seen in $11 \%$ in follow up, VA of $6 / 60$ to $3 / 60$ was seen in $n=2(3.3 \%)$ observed in $7.5 \%$ in follow up,VA of $3 / 60$ to $1 / 60$ was seen in $n=8(13.33 \%)$ decreased to $5.8 \%$ in follow up, VA of $1 / 60$ to perception of light was seen in $n=17(28.33 \%)$ which decreased to $n=8(13.33 \%)$ at 3 months follow up. NPL was seen in $6.66 \%(n=4)$ at the time of presentation.1 case developed endophthalmitis during follow up period. Rapoport et al. ${ }^{19}$ in a study of eye injuries in children in Israel concluded visual acuity at the time of hospital discharge better than $6 / 30$ in the majority of eyes, while $11 \%$ had a VA of less than $6 / 60$, and no light perception was seen in $3 \%$ cases and enophthalmitis in $1.4 \%$.

The limitations of study are small sample size, visual acuity couldnot be assessed in 3 cases and surgeries were performed by different surgeons.

\section{CONCLUSIONS}

Severe ocular trauma is one of the major causes of preventable ocular blindness. Paediatric age group less than 10 years and young earning males are frequently affected. Injuries at play, work and road traffic accidents comprise the main causes. Nearly half had severe visual impairment and worse at presentation and 33.33\% in follow up. We hope to improve both primary prevention of injury and secondary earlier and meticulous management for affected cases. Different legislation acts and traffic regulations, use of protective eye wears, health education targeting the vulnerable age group regarding prevention and seeking early medical help, adult supervision of children shall minimize or prevent morbidity due to severe trauma.This study may help to increase public awareness and make some contribution in prevention and management of eye injuries.

\section{ACKNOWLEDGEMENT}

Our immense thanks to colleagues of other department for referral of severe ocular trauma cases. We are grateful to all other staffs for help and support.

\section{REFERENCES}

1. Katz J, Tielsch JM. Lifetime prevalence of ocular injuries from the Baltimore Eye Survey.ArchOphthalmol. 1993;111:156468. DOI: 10.1001/archopht.1993.01090110130038

2. Schein OD, Hibberd PL, Shingleton BJ, Kunzweiler T, Frambach DA, Seddon JM et al. The spectrum and burden of ocular injury. Ophthalmology. 1988; 95:300-5.DOI: 10.1016/s0161-6420(88)33183-0.

3. Thylefors B. Epidemiological patterns of ocular trauma. Aust N Z J Ophthalmol. 1992; 20:95-98. DOI:10.1111/j.1442-9071.1992.tb00718.x.

4. Negrel AD, Thylefors B. The global impact of eye injuries. Ophthalmic Epidemiol. 1998;5:143-69. DOI:10.1076/ opep.5.3.143.8364.

5. Alfonso EC, Arieta CL, Blankenship GW, et al. Ocular Trauma Epidemiology and prevention. In: Van Newkirk M, Alfonso EC, Chuang EL, et al., editors. International Ophthalmology: American Academy of ophthalmology. $3^{\text {rd }}$ ed. San Francisco: 2005; 121-34.

6. Dandona L, Dandona R, Srinivas M,John RK, McCarty CA, Rao GN. Ocular trauma in an urban population in southern India: the Andhra Pradesh eye disease study. Clin Exp Ophthalmol. 2000;28:350-6. DOI:10.1046/j.1442-9071.2000.00334.x.

7. May DR, Kuhn FP, Morris RE, Witherspoon CD, Danis RP, Matthews GP, et al. The epidemiology of serious eye injuries from the United States Eye Injury Registry. Graefes Arch Clin Exp Ophthalmol. 2000; 238:153-7. DOI:10.1007/ pI00007884.

8. Brilliant LB, Pokhrel RP, Grasset NC, Lepkowski JM, Kolstad A, Hawks W et al. Epidemiology of blindness in Nepal. Bull World Health Organ. 1985; 63(2):375-86. PMID:3874717.

9. Ilsar M, Chirambo M, Belkin M. Ocular injuries in Malawi. Br 
J Ophthalmol. 1982;66: 145-8. DOI:10.1136/bjo.66.2.145 PMID:7059557.

10. Voon LW, See J, Wong TY. The Epidemiology of ocular trauma in Singapore: perspective from the emergency service of a large tertiary hospital. Eye. 2001;15:75- 81. DOI:10.1038/ eye.2001.18

11. Onyekwe LO. Spectrum of Eye Injuries In Children in Guinness Eye Hospital, Onitsha. Nig J Surg Res. 2001;3:12632. DOI: $10.4314 /$ njsr.v3i3.12233

12. Khatry SK, Lewis AE, Schein OD, Thapa MD, Pradhan EK, Katz J. The epidemiology of ocular trauma in rural Nepal. Br J Ophthalmol. 2004;88:456-60. DOI:10.1136/ bjo. 2003.030700

13. Vats S, Murthy GVS, Chandra M, Gupta SK, Vashist P, Gogoi M. Epidemiological study of ocular trauma in an urban slum population in Delhi, India. Indian J Ophthalmol. 2008;56:313-6. DOI:10.4103/0301-4738.41413

14. McCarty CA, FU CL, Taylor HR. Epidemiology of ocular trauma in Australia. Ophthalmology. 1999;106:1847-52. DOI: 10.1016/S0161-6420(99)90361-5

15. Desai P, MacEwen CJ, Baines P, Minassian DC. Incidence of cases of ocular trauma admitted to hospital and incidence of blinding outcome. Br J Ophthalmol. 1996;80:592- 6. DOI:10.1136/bjo.80.7.592

16. Desai P, MacEwen CJ, Baines P, Minassian DC. Epidemiology and implications of ocular trauma admitted to hospital in
Scotland. J Epidemiol Community Health. 1996;50:436-41. DOI:10.1136/jech.50.4.436

17. Kinderan YV, Shrestha E, Maharjan IM, Karmacharya S. Pattern of ocular trauma in the western region of Nepal. Nepal J Ophthalmol. 2012;4(1):5-9. DOI:10.3126/nepjoph. v4i1.5843

18. Misra S, Nandwani R, Gogri P, Misra N. Clinical profile and visual outcome of ocular injuries in a rural area of western India. Australas Med J. 2013;6(11):560-4. DOI: 10.4066/ AMJ.2013.1876 PMID:24348872.

19. Rapoport I, Romem M, Kinek M, Koval R, Teller J, Belkin $\mathrm{M}$ et al. Eye injuries in children in Israel: A Nationwide collaborative study. Arch Ophthalmol. 1990;108(3):376-9. DOI:10.1001/archopht.1990.01070050074034

20. Godar ST, Kaini KR, Amatya P, Joshi K, Singh L. Magnitude of ocular trauma in a tertiary care hospital of western Nepal. Nepal Journal of Medical Sciences. 2013;2(2):140-3. DOI: https://doi.org/10.3126/njms.v2i2.8964

21. Sthapit PR, Marasini S, Khoju U, Thapa G, Nepal BP. Ocular trauma in patients presenting to Dhulikhel Hospital. Kathmandu University Medical Journal. 2011;9(1):54-7. DOI:https://doi.org/10.3126/kumj.v9i1.6264

22. Malla BK. Structural changes in ocular trauma and the visual outcome. Kathmandu Univ Med J. 2004;2(2):113-8. PMID:15821376. 